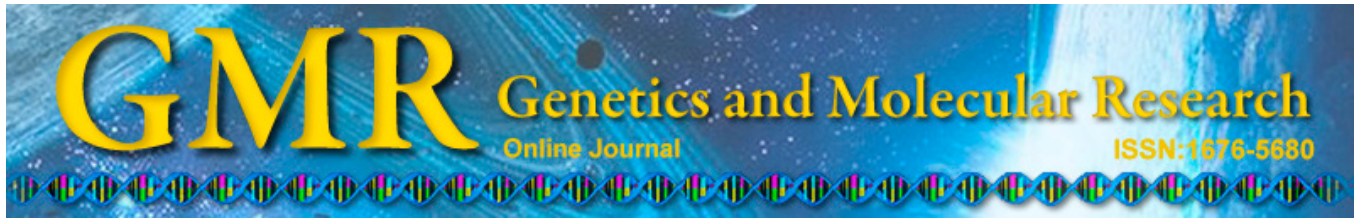

\title{
Effects of HIF prolyl-hydroxylase-2 gene silencing on HCG-induced vascular endothelial growth factor expression in luteal cells
}

\author{
Z.H. Zhang ${ }^{1,2}$, D.Z. Yin ${ }^{2}$, X.S Pang ${ }^{2}$ and Z.C. Wang ${ }^{1}$ \\ ${ }^{1}$ Provincial Key Laboratory for Developmental Biology and Neurobiology, \\ College of Life Science, Fujian Normal University, Fuzhou, China \\ ${ }^{2}$ Laboratory of Animal Reproduction, Department of Animal Science, \\ College of Animal Science and Technology, \\ Anhui Science and Technology University Bengbu, China
}

Corresponding author: Z.C. Wang

E-mail: zcwang@fjnu.edu.cn

Genet. Mol. Res. 14 (4): 16744-16755 (2015)

Received August 2, 2015

Accepted October 9, 2015

Published December 14, 2015

DOI http://dx.doi.org/10.4238/2015.December.14.2

\begin{abstract}
Vascular endothelial growth factor (VEGF)-dependent angiogenesis plays a crucial role in corpus luteum formation and its functional maintenance in mammalian ovaries. We recently reported that activation of hypoxia-inducible factor (HIF)- $1 \alpha$ signaling contributes to the regulation of VEGF expression in luteal cells (LCs) in response to human chorionic gonadotropin (HCG). We examined whether HIF prolyl-hydroxylase (PHD)-2 gene silencing induces VEGF expression in LCs and enhanced its expression induced by HCG in LCs. Using real-time polymerase chain reaction and western blot analysis, we measured the expression of PHD-2 to confirm plasmid PHD-2 shRNA transfection and protein expression and investigated the changes in HIF$1 \alpha$ and VEGF expression after treatment with HCG and PHD-2 shRNA transfection. After PHD-2 shRNA transfection, PHD-2 expression was significantly lower than that in control groups with or without HCG treatment, while a significant increase in VEGF mRNA was observed
\end{abstract}


compared to in controls, indicating that PHD-2 plays an important role in VEGF regulation. Additionally, changes in VEGF mRNA expression were consistent with the expression levels of HIF-1 $\alpha$ protein, not HIF$1 \alpha$ mRNA, which is regulated by HIF prolyl-hydroxylase-mediated degradation. Our results indicate that PHD-2 gene silencing can induce VEGF expression in LCs and HCG-induced VEGF expression can be further enhanced by PHD-2 gene silencing through an HIF- $1 \alpha$-mediated mechanism in LCs. This PHD-2-mediated transcriptional activation may be important for regulating VEGF expression through HIF-1 $\alpha$ signaling in LCs during corpus luteum development in mammals.

Key words: HIF prolyl-hydroxylase-2; Hypoxia-inducible factor-1 $\alpha$; Human chorionic gonadotropin; Vascular endothelial growth factor; Luteal cells

\section{INTRODUCTION}

Vascular endothelial growth factor (VEGF) plays a fundamental role in physiological angiogenesis and vascularization of the follicular luteinizing granulosa layer during corpus luteum (CL) formation (Christenson and Stouffer, 1997; Kaczmarek et al., 2005; Shimizu and Miyamoto, 2007; Shimizu et al., 2007). Because inhibition of VEGF in vivo during the luteal phase prevents luteal angiogenesis and subsequent progesterone secretion (Wulff et al., 2001; Fraser et al., 2005, 2006; Duncan et al., 2008), while excess VEGF generation during the vascularization of multiple follicles is also thought to cause ovarian hyperstimulation syndrome (Neulen et al., 1995; Nastri et al., 2010). Therefore, the molecular regulation of luteal VEGF expression is very important.

We recently reported that HIF- $1 \alpha$ contributes to the transcriptional regulation of VEGF in luteal cells (LCs) (Zhang et al., 2011a,b). Hypoxia-inducible factor (HIF)-1, a helixloop-helix transcriptional factor consisting of HIF- $1 \alpha$ and HIF-1 $\beta$, has been cloned and characterized as a transcriptional activator of many oxygen-sensitive genes, such as erythropoietin, heme oxygenases, transferrin, and several glycolytic enzymes (Wenger et al., 1996; Zhang et al., 2011a,b). It has been suggested that HIF-1 $\alpha$ is an inducible protein by a decrease in tissue or cellular $\mathrm{O}_{2}$. HIF- $1 \beta$ is not inducible, but it can be bound to HIF- $1 \alpha$ to form a dimer that activates the transcription of many genes containing cis-hypoxia-response element in their promoter or enhancer regions. Previous chromatin immunoprecipitation results have indicated that estrogen can simultaneously induce the recruitment of both HIF-1 ( $\alpha$ and $\beta$ ) to the upstream hypoxia-response element and ER $\alpha$ to the proximal GC-rich region of the VEGF promoter, which mediates transcriptional activation of the mouse VEGF gene (Kazi et al., 2005; Kazi and Koos, 2007; Molitoris et al., 2009).

It has been demonstrated that HIF prolyl-hydroxylases are the major enzymes promoting the degradation of HIF-1 $\alpha$ (Bruick and McKnight, 2001; Ivan et al., 2001; Jaakkola et al., 2001). HIF prolyl-hydroxylases catalyze site-specific proline hydroxylation of HIF-1 $\alpha$, which is recognized and targeted for degradation by the ubiquitin-proteasome pathway. Three isoforms of HIF prolyl-hydroxylase, including prolyl hydroxylase domain-containing proteins 1, 2, and 3 (PHD-1, 2, and 3), have been identified (Bruick and McKnight, 2001; Ivan et al., 2001; Jaakkola et al., 2001; Epstein et al., 2001). Our previous study indicated that PHD-2 
is most abundantly expressed in LCs (Zhang et al., 2011b; Pang et al., 2011) and that PHD2 is involved in regulating HIF-1 $\alpha$ levels (Wang et al., 2010) and is important in angiogenesis (Chan and Giaccia, 2010).

Given the important role of PHD-2 in regulating HIF-1 $\alpha$ levels, we hypothesized that the PHD-2 signaling pathway contributes to VEGF expression in ovarian angiogenesis and that silencing of the PHD-2 gene enhances the expression of VEGF induced by HCG in LCs. We examined the effect of PHD-2 shRNA transfection and HCG on the expression of HIF$1 \alpha$, and determined the role of PHD2 in HCG-induced activation of HIF-1 $\alpha$ by transfection of PHD-2 shRNA into LCs. We also determined the changes in VEGF mRNA level in each group. Our results demonstrate that PHD-2 is a mediator of cellular HIF-1 $\alpha$ and its target gene VEGF in LCs, which may be an important mechanism for regulating VEGF-dependent angiogenesis during CL development in mammals.

\section{MATERIAL AND METHODS}

\section{Animals}

Twenty-five-day-old female Sprague-Dawley (SD) rats (Fuzhou Animal Center, Fuzhou, China) were used in the present study. All animals were maintained under a 12-h light/ dark schedule with food and water available ad libitum. The study was conducted in accordance with guidelines of the Institutional Animal Care and Use Committee and was approved by the Ethics Committee on Animal Experimentation of the University. All efforts were made to minimize animal discomfort and to reduce the number of animals used.

\section{Isolation and culture of rat LCs}

Rat LCs were isolated and cultured as described previously (Conti et al., 1977; Thomas et al., 1978; Pepperell et al., 2003). Briefly, the rats received a subcutaneous injection of 5 IU equine chorionic gonadotropin (Sigma-Aldrich, St. Louis, MO, USA) and a 10 IU ovulatory dose of human chorionic gonadotropin (HCG; Sigma) $64 \mathrm{~h}$ later. Ovaries were obtained 5 days after HCG injection and minced with a razor blade. Tissue was digested in medium 199 (GIBCO, Grand Island, NY, USA; contains Earle's salts but no L-glutamine and no sodium bicarbonate) containing $1 \%$ fetal calf serum (GICBO) and $2000 \mathrm{IU}$ collagenase (GIBCO) plus $3000 \mathrm{IU}$ DNase (Sigma) per gram of tissue for $1 \mathrm{~h}$ at $37^{\circ} \mathrm{C}$ under $95 \%$ air with $5 \% \mathrm{CO}_{2}$. The contents of the flask were filtered through nylon mesh (BD Biosciences, Franklin Lakes, NJ, USA) and centrifuged (100 g, $5 \mathrm{~min})$; the supernatant fraction was discarded and the pellet was washed 3 times with fresh medium. The final cell concentration was $10^{6}$ cells per $\mathrm{mL}$ and cell incubation was carried out on 6-well culture plates. Cell numbers were determined using a hemocytometer and cell viability was $>90 \%$ as assessed by exclusion of trypan blue dye.

\section{Transfection of PHD-2 shRNA plasmid into cells}

Plasmids encoding rat full-length PHD2 cDNA were generous gifts from Dr. Ningjun $\mathrm{Li}$ (Virginia Commonwealth University). The expression and function of rat PHD2 protein by the plasmids has been validated in previous studies (Huang et al., 2002; Percy et al., 2006; Li et al., 2007; Wang et al., 2010). Plasmid transfections were performed using lipids (DOTAP/ 
DOPE, Avanti Polar Lipids, Inc., Alabaster, AL, USA) according to manufacturer instructions. Briefly, $5 \mu \mathrm{g}$ DNA was mixed with lipid solution at a ratio of 1:10 (DNA:lipid, w/w) in serum-free culture medium (5 mL in a $10-\mathrm{cm}$ dish). Cells were incubated with this transfection medium for $5 \mathrm{~h}$ and switched to normal medium for another $16 \mathrm{~h}$. The cells were used in subsequent experiments.

\section{Cell treatment and experimental groups}

After plasmid transfection, the cells were placed in serum-free medium containing $100 \mu \mathrm{M}$ HCG. After HCG treatment for $18 \mathrm{~h}$, the cells were harvested for protein and RNA isolation as described below.

\section{RNA extraction and quantitative reverse transcription-polymerase chain reaction (RT-PCR) analysis of PHD-2, HIF-1 $\alpha$, and VEGF mRNA levels}

Total RNA was extracted using TRIzol solution (Life Technologies, Inc., Carlsbad, CA, USA) and then reverse-transcribed (cDNA Synthesis Kit, Bio-Rad, Hercules, CA, USA). The RT products were amplified using SYBR Green for PHD2 (forward primer 5'-CTG GGA CGC CAA GGT GA-3' and reverse primer 5'- CAA TGT CAG CAA ACT GG-3'; GenBank accession No. NM178334), HIF-1 $\alpha$ (forward primer 5'-CTG GCA CGG GGA TGA TAC AGC-3' and reverse primer 5'-TCT CAT CCA TTG ACT GCC CCA G-3'; GenBank accession No. AF057308) and VEGF (forward primer 5'-ACG AAG CGC AAG AAA TCC C-3' and reverse primer 5'-TTA ACT CAA GCT GCC TCG CC-3'; GenBank accession No. M32167) using an iCycler iQ Real Time PCR Detection System (Bio-Rad). The level of 18S rRNA (forward primer 5'-CGC CGC TAG AGG TGA AAT TC-3' and reverse primer 5'-TCT TGG CAA ATG CTT TCG C-3'; GenBank accession No. M11188) was used as an endogenous control. Relative gene expression was calculated in accordance with the $\Delta \Delta \mathrm{Ct}$ method. Relative mRNA levels were expressed as $2^{-\Delta \Delta C t}$.

\section{Preparation of nuclear extracts and cytosolic protein and western blot analyses for protein levels of HIF-1 $\alpha$ and PHD2}

Nuclear protein was prepared as described previously (Li et al., 2007; Wang et al., 2010; Zhang et al., 2011a). Cytosolic protein and nuclear protein were collected separately. The cytosolic protein was used for western blot analyses of PHD2. The nuclear fraction was used for western blot analyses of HIF-1 $\alpha$. Primary antibodies used in the present study included HIF-1 $\alpha$ (monoclonal, Novus Biologicals, 1:300 dilution) and PHD2 (rabbit polyclonal, Novus Biologicals, Littleton, CO, USA; 1:300).

\section{Determination of HIF-4-prolyl hydroxylase activity}

HIF-1 $\alpha$-peptide-specific conversion of 2-oxoglutarate into succinate provides a hydroxyl group for HIF-1 $\alpha$ to be prolyl hydroxylated. This reaction has been widely used to determine PHD activity by measuring the HIF-1 $\alpha$-dependent conversion rate of 2 -oxoglutarate into succinate (Richard-Fiardo et al., 2008; Yi et al., 2009; Wang et al., 2010). 


\section{Statistics}

Data are reported as means \pm standard deviation. Significance of differences in mean values within and between multiple groups was evaluated using analysis of variance followed by a Duncan's multiple range test. $\mathrm{P}<0.05$ was considered to be statistically significant.

\section{RESULTS}

\section{PHD-2 mRNA expression in LCs transfected with PHD-2 shRNA plasmid}

The results showed that HCG increased PHD-2 mRNA expression to some degree (Figure 1), and a significant decrease in PHD-2 mRNA was observed after PHD-2 shRNA transfection in LCs with or without HCG treatment, indicating the high transfection efficiency of PHD-2 shRNA plasmid (Figure 1).

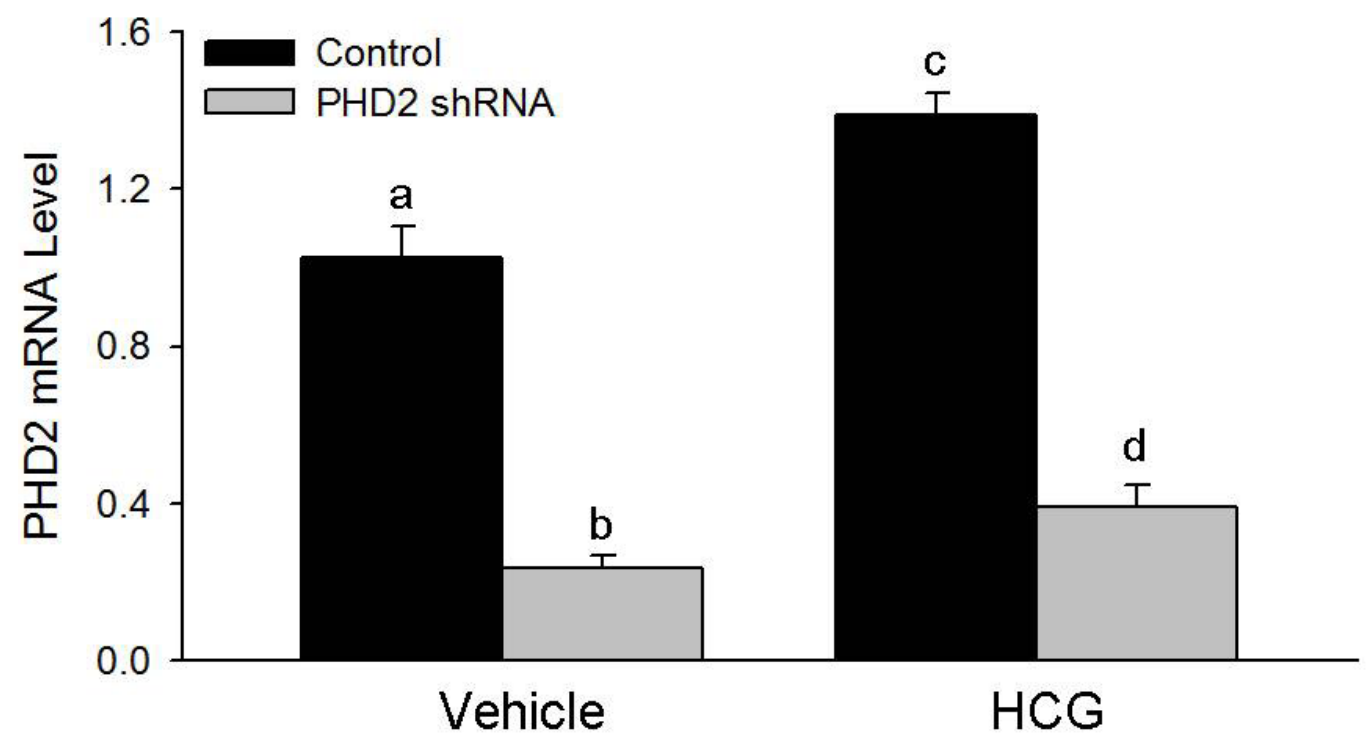

Figure 1. PHD-2 mRNA expression in LCs transfected with PHD-2 shRNA plasmid. The relative mRNA levels of PHD-2 by Real-time PCR analysis. Each value represents the mean \pm SD. One-way analysis of variance (ANOVA) was used to analyze the data. Different superscripts denote significant values between the other group $(\mathrm{P}<0.05)$ by Duncan's mutiple range test. $\mathrm{N}=6$ batches of cells.

\section{PHD-2 protein expression and PHD activity in LCs transfected with PHD-2 shRNA plasmid}

To further confirm the role of PHD-2 in PHD-2 shRNA-transfected LCs, we detected PHD-2 protein levels and PHD-2 biological activity in each group (Figures 2 and 3). Our results showed that HCG had no effect on PHD-2 protein expression (Figure 2), while a significant decrease in PHD-2 protein was observed after PHD-2 shRNA transfection in LCs with or without HCG treatment compared with controls (Figure 2). Furthermore, PHD-2 shRNA transfection significantly decreased the PHD biological activity of whole proteins in each 
group compared with each control (Figure 3), further indicating that the PHD-2 shRNA plasmid functioned well in the present study.
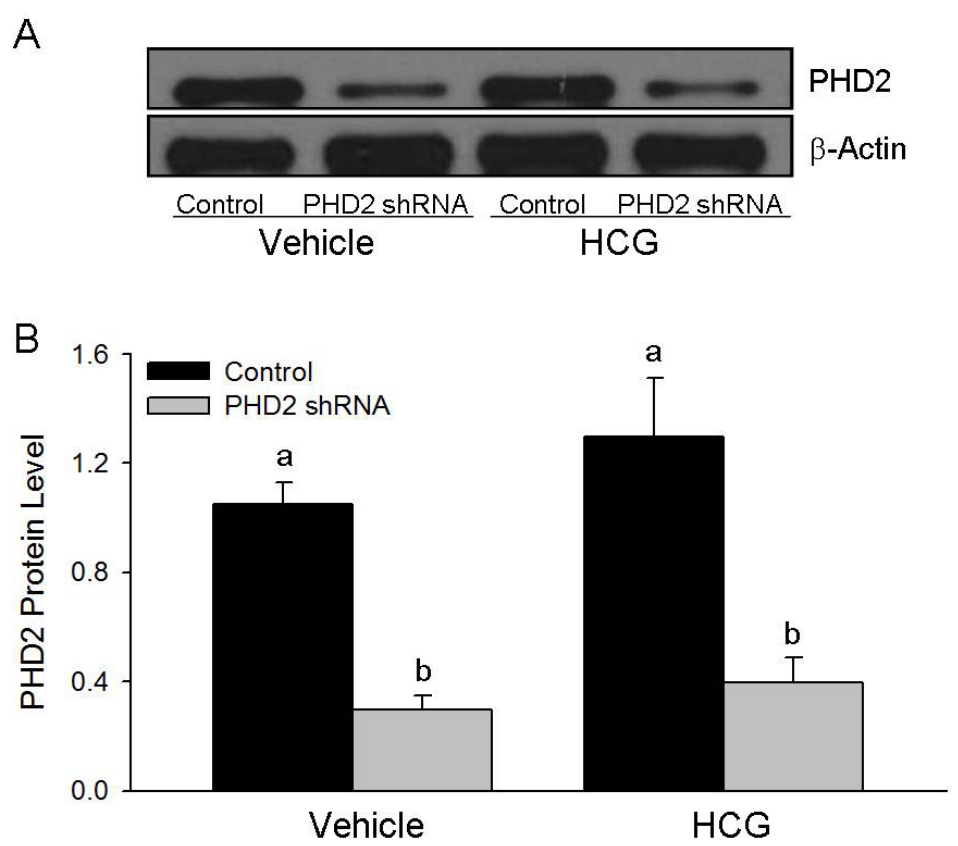

Figure 2. PHD-2 protein expression in LCs transfected with PHD-2 shRNA plasmid. A. Representative ECL gel documents of Western blot analyses depicting the protein level of PHD-2. B. Summarized intensities of PHD-2 blot normalized to control. Each value represents the mean \pm SD. One-way analysis of variance (ANOVA) was used to analyze the data. Different superscripts denote significant values between the other group $(\mathrm{P}<0.05)$ by Duncan's mutiple range test. $\mathrm{N}=6$ batches of cells.

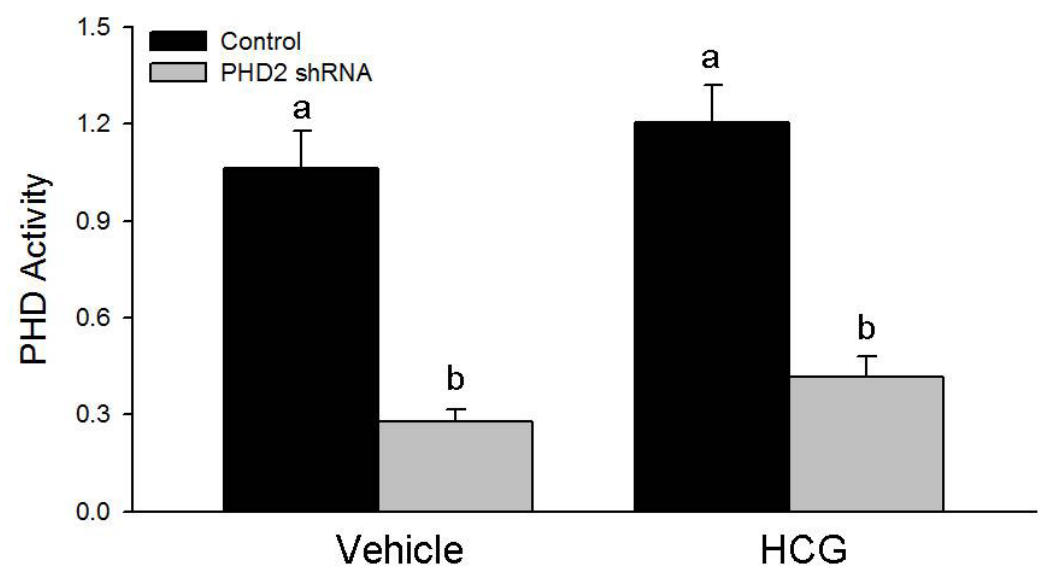

Figure 3. PHD activity in LCs transfected with PHD-2 shRNA plasmid. HIF-4-prolyl hydroxylase activity in each group by $\left[{ }^{14} \mathrm{C}\right]-2-\mathrm{OG}$ converstion rate. Each value represents the mean $\pm \mathrm{SD}$. One-way analysis of variance (ANOVA) was used to analyze the data. Different superscripts denote significant values between the other group (P $<0.05$ ) by Duncan's mutiple range test. $\mathrm{N}=6$ batches of cells. 


\section{Effects of HCG and PHD2 shRNA transfection on VEGF mRNA level in LCs}

In the present study, PHD-2 shRNA transfection induced VEGF mRNA expression in LCs (Figure 4), indicating that PHD-2 plays an important role in the regulation of VEGF expression during CL development. In addition, HCG significantly increased VEGF mRNA expression in LCs (Figure 4), which is consistent with our previous reports (Zhang et al., 2011b; Pang et al., 2011). Further analysis showed that PHD-2 shRNA transfection enhanced HCG-induced VEGF mRNA expression (Figure 4), indicating that VEGF mRNA expression is regulated through different mechanisms.

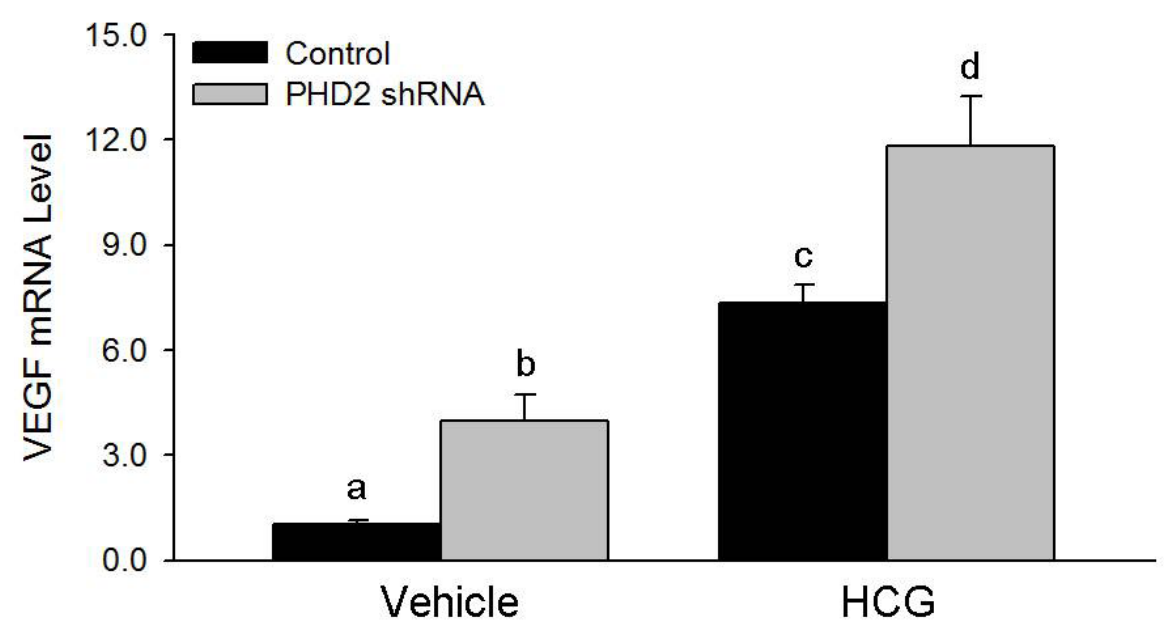

Figure 4. Effects of HCG and PHD2 shRNA transfection on VEGF mRNA level in LCs. The relative mRNA levels of VEGF by real-time PCR analysis. Each value represents the mean \pm SD. One-way analysis of variance (ANOVA) was used to analyze the data. Different superscripts denote significant values between the other group ( $\mathrm{P}$ $<0.05$ ) by Duncan's mutiple range test. $\mathrm{N}=6$ batches of cells.

\section{Effects of HCG and PHD-2 shRNA transfection on HIF-1 $\alpha$ mRNA level in LCs}

In the present study, HCG significantly increased HIF-1 $\alpha$ mRNA expression in LCs, as described in previous reports (Zhang et al., 2011b; Pang et al., 2011). To improve the understanding of the important role of PHD2 in LCs, we examined HIF-1 $\alpha$ mRNA levels in LCs transfected with PHD-2 shRNA plasmid (Figure 5). Interestingly, a dramatic increase in VEGF mRNA level was found in PHD2 shRNA-transfected LCs (Figure 4), while HIF-1 $\alpha$ mRNA showed no obvious changes with or without HCG treatment compared with controls (Figure 5).

\section{Effects of HCG and PHD-2 shRNA transfection on HIF-1a protein levels in LCs}

HIF prolyl-hydroxylases have been shown to be major enzymes that promote the degradation of HIF-1 $\alpha$ (Bruick and McKnight, 2001; Ivan et al., 2001; Jaakkola et al., 2001; Epstein et al., 2001); therefore, we examined HIF-1 $\alpha$ protein levels in each group (Figure 6). A significant increase in HIF-1 $\alpha$ protein was observed in PHD-2 shRNA-transfected LCs, indicating that PHD-2 regulates VEGF expression via the HIF- $\alpha$ pathway in LCs during ovarian angiogenesis (Li et al., 2007; Wang et al., 2010; Zhang et al., 2011b; Pang et al., 2011). 


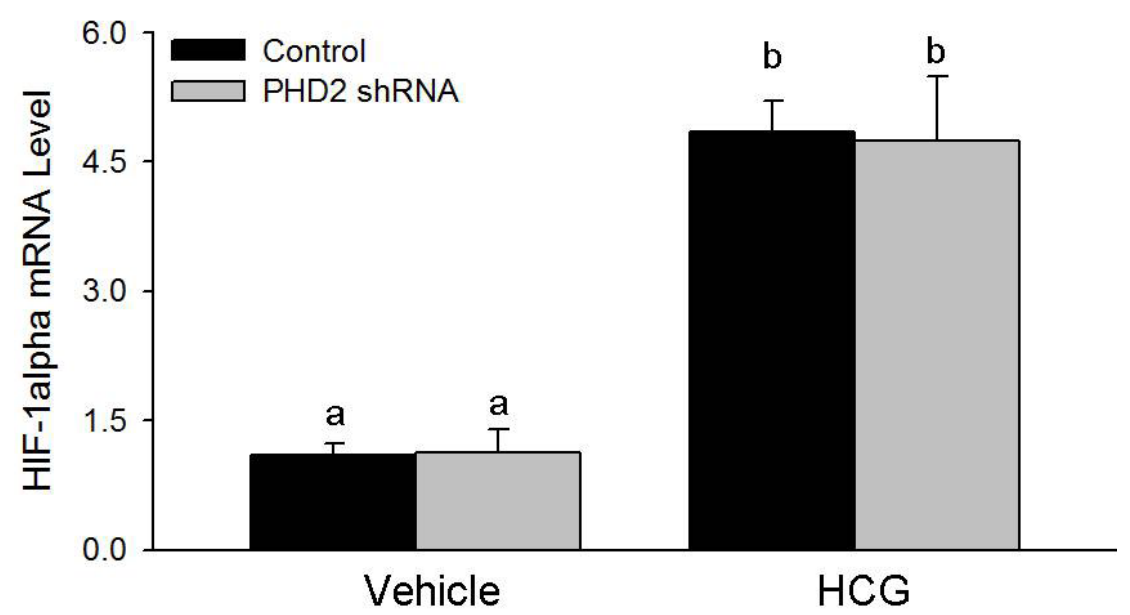

Figure 5. Effects of HCG and PHD2 shRNA transfection on HIF-1alpha mRNA level in LCs. The relative mRNA levels of HIF-1alpha by real-time PCR analysis. Each value represents the mean \pm SD. One-way analysis of variance (ANOVA) was used to analyze the data. Different superscripts denote significant values between the other group $(\mathrm{P}<0.05)$ by Duncan's mutiple range test. $\mathrm{N}=6$ batches of cells.

A

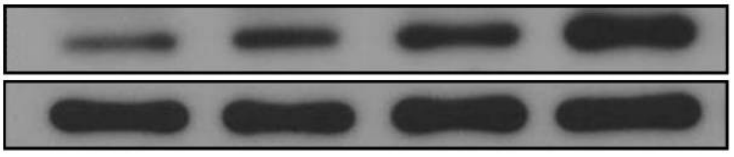

HIF-1alpha

Control PHD2 shRNA Control PHD2 shRNA

Vehicle HCG

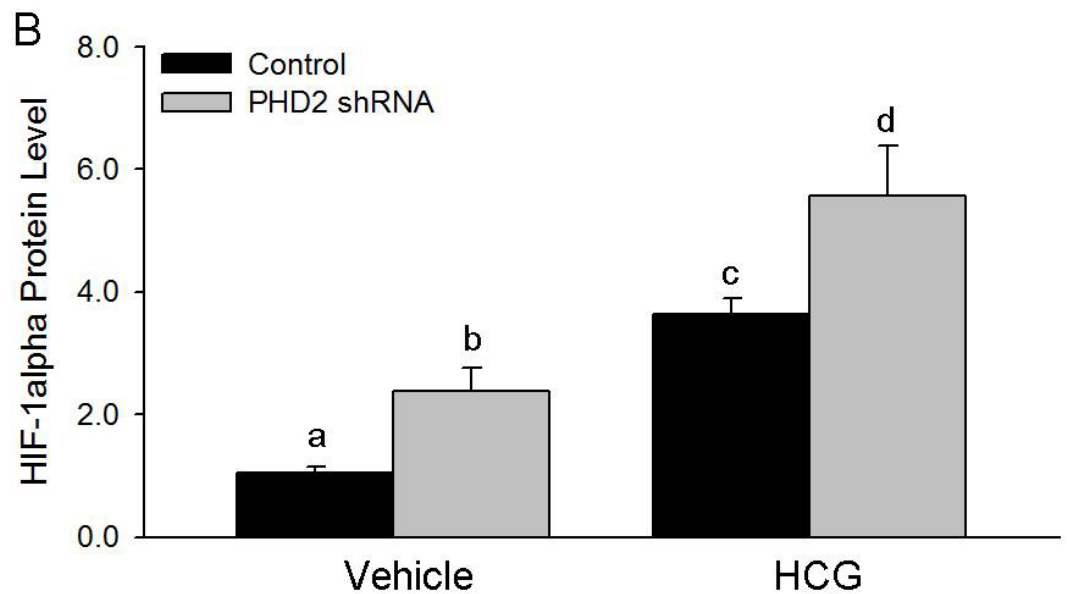

Figure 6. Effects of HCG and PHD-2 shRNA transfection on HIF-1alpha protein levels in LCs. A. Representative ECL gel documents of Western blot analyses depicting the protein level of HIF-1alpha. B. Summarized intensities of HIF-1alpha blot normalized to control. Each value represents the mean $\pm \mathrm{SD}$. One-way analysis of variance (ANOVA) was used to analyze the data. Different superscripts denote significant values between the other group (P $<0.05$ ) by Duncan's mutiple range test. $\mathrm{N}=6$ batches of cells. 


\section{DISCUSSION}

The results of the present study demonstrate that silencing of the PHD-2 gene induced VEGF and HIF-1 $\alpha$ expression in LCs, suggesting that PHD2-mediated VEGF expression via the HIF-1 $\alpha$ pathway is an important mechanism of VEGF-dependent angiogenesis during the CL development in mammals.

The CL is a temporary endocrine structure in mammals that plays an important role in the female reproductive cycle and is formed from a ruptured and ovulated follicle with rapid angiogenesis (Young et al., 2000; Wulff et al., 2001; Fraser et al., 2005; Nishimura and Okuda, 2010; Zhang et al., 2011a). VEGF is thought to play a critical role in the regulation of normal and abnormal angiogenesis in the ovary (Neulen et al., 1995; Lee et al., 1997; Fraser et al., 2005; Kaczmarek et al., 2005; Shimizu and Miyamoto, 2007; Shimizu et al., 2007; van den Driesche et al., 2008; Zhang et al., 2011a), particularly in the newly formed CL. Our previous experiments provided direct evidences that VEGF is transcriptionally activated by an HIF-1-mediated mechanism in LCs under hypoxia (Zhang et al., 2011a), which is caused by ovulation of a ruptured follicle with bleeding and an immature vasculature (Kaczmarek et al., 2005; Nishimura and Okuda, 2010). However, many reports have also shown that reproductive hormones such as HCG take part in the primary regulation of VEGF expression in the ovary. For example, VEGF mRNA expression in human luteinized granulosa cells has been shown to be dose- and time-dependently enhanced by HCG in vitro (Neulen et al., 1995; Nastri et al., 2010). Chronic or acute exposure to HCG directly stimulates VEGF production and secretion in monkeys (Christenson and Stouffer, 1997) and human luteinized granulosa cells (Neulen et al., 1995; Lee et al., 1997; Wulff et al., 2001; Nastri et al., 2010). Administration of a gonadotropin-releasing hormone antagonist decreased VEGF mRNA expression in the monkey CL (Ravindranath et al., 1992). In addition, luteal vascularization and development of ovarian hyperstimulation syndrome are dependent on luteinizing hormone/HCG stimulation (Neulen et al., 1995; Nastri et al., 2010). Furthermore, in a fully formed, highly vascular CL, HCG also upregulates VEGF expression (Wulff et al., 2001). Therefore, the present study examined the induced effect of HCG on VEGF mRNA expression in LCs. Interestingly, we found that VEGF expression was induced by HCG in LCs and HCG-stimulated HIF-1 $\alpha$ protein expression, which was highly correlated with VEGF expression, indicating that HCG stimulated VEGF expression via the HIF-1 $\alpha$ signaling pathway, which agrees with our previous report (Zhang et al., 2011b; Pang et al., 2011).

Many studies have already indicated that HIF-1 $\alpha$ regulates the expression of many genes whose protein products play critical roles in developmental and physiological processes, including angiogenesis, erythropoiesis, glycolysis, iron transport, and cell proliferation/ survival (Zhong et al., 2000; Wulff et al., 2001; Yaba et al., 2008; Miyazawa et al., 2009, 2010; Nishimura and Okuda, 2010). Because HIF-1 $\alpha$ activates the transcription of VEGF, which is required for angiogenesis, it is possible that HCG may mediate angiogenesis via the HIF-1 $\alpha$ /VEGF pathway. In addition to a detailed exploration of the downstream mechanism of HIF-1 $\alpha$, recent studies have clarified the upstream process modulated by PHDs, which regulates HIF-1 $\alpha$ degradation through the ubiquitin-proteasome pathway. Particularly, PHD2 has drawn considerable attention because it is considered to be the key oxygen sensor in all PHD enzymes identified (Wang et al., 2010; Chan and Giaccia, 2010). Knockdown of PHD2 resulted in elevated HIF protein, and several recent studies have highlighted the importance of PHD2 in tumorigenesis (Chan and Giaccia, 2010). In this study, we found that HCG activated 
HIF-1 $\alpha$, and silencing of the PHD-2 gene enhanced this activation of HIF- $1 \alpha$ and its target gene VEGF after HCG treatment. These results indicate that PHD2 is involved in HIF-1 $\alpha$ mediated gene activations in LCs treated with HCG, which may be a novel mechanism for VEGF-dependent angiogenesis during mammalian CL development.

In summary, the present study demonstrated that HCG induces HIF- $1 \alpha$ and VEGF expression in LCs, which can be enhanced by silencing of the PHD-2 gene. This PHD-2-mediated VEGF expression may be an important mechanism for VEGF-dependent angiogenesis during CL formation in the mammalian ovary. Furthermore, PHD-2 antagonism may be useful for the development of novel treatments for fertility control and for some types of ovarian dysfunction (Miyazawa et al., 2009, 2010; Chan and Giaccia, 2010), particularly those conditions characterized by pathological angiogenesis and excessive vascular permeability, such as polycystic ovarian syndrome, ovarian hyperstimulation syndrome, and ovarian neoplasia.

\section{ACKNOWLEDGMENTS}

Research supported by the National Natural Science Foundation of China (\#31101032 and \#31271255), Program for New Century Excellent Talents in University of Ministry of Education of China (\#NCET-120614), Doctoral Foundation of the Ministry of Education in China (\#20113503120002), and Fujian Provincial Science and Technology Projects of the Department of Education (\#AJ11041). We particularly thank Dr. Ningjun Li from Virginia Commonwealth University in the USA for providing the PHD-2 shRNA and control plasmids.

\section{REFERENCES}

Bruick RK and McKnight SL (2001). A conserved family of prolyl-4-hydroxylases that modify HIF. Science 294: 13371340.

Chan DA and Giaccia AJ (2010). PHD2 in tumour angiogenesis. Br. J. Cancer 103: 1-5.

Christenson LK and Stouffer RL (1997). Follicle-stimulating hormone and luteinizing hormone/chorionic gonadotropin stimulation of vascular endothelial growth factor production by macaque granulosa cells from pre- and periovulatory follicles. J. Clin. Endocrinol. Metab. 82: 2135-2142.

Conti M, Harwood JP, Dufau ML and Catt KJ (1977). Effect of gonadotropin-induced receptor regulation on biological responses of isolated rat luteal cells. J. Biol. Chem. 252: 8869-8874.

Duncan WC, van den Driesche S and Fraser HM (2008). Inhibition of vascular endothelial growth factor in the primate ovary upregulates hypoxia-inducible factor-1alpha in the follicle and corpus luteum. Endocrinology 149: 3313-3320.

Epstein AC, Gleadle JM, McNeill LA, Hewitson KS, et al. (2001). C. elegans EGL-9 and mammalian homologs define a family of dioxygenases that regulate HIF by prolyl hydroxylation. Cell 107: 43-54.

Fraser HM, Bell J, Wilson H, Taylor PD, et al. (2005). Localization and quantification of cyclic changes in the expression of endocrine gland vascular endothelial growth factor in the human corpus luteum. J. Clin. Endocrinol. Metab. 90: 427-434.

Fraser HM, Wilson H, Wulff C, Rudge JS, et al. (2006). Administration of vascular endothelial growth factor Trap during the 'post-angiogenic' period of the luteal phase causes rapid functional luteolysis and selective endothelial cell death in the marmoset. Reproduction 132: 589-600.

Huang J, Zhao Q, Mooney SM and Lee FS (2002). Sequence determinants in hypoxia-inducible factor-1alpha for hydroxylation by the prolyl hydroxylases PHD1, PHD2, and PHD3. J. Biol. Chem. 277: 39792-39800.

Jaakkola P, Mole DR, Tian YM, Wilson MI, et al. (2001). Targeting of HIF-alpha to the von Hippel-Lindau ubiquitylation complex by O2-regulated prolyl hydroxylation. Science 292: 468-472.

Ivan M, Kondo K, Yang H, Kim W, et al. (2001). HIFalpha targeted for VHL-mediated destruction by proline hydroxylation: implications for O2 sensing. Science 292: 464-468.

Kaczmarek MM Schams D and Ziecik AJ (2005). Role of vascular endothelial growth factor in ovarian physiology - an overview. Reprod. Biol. 5: 111-136. 
Kazi AA and Koos RD (2007). Estrogen-induced activation of hypoxia-inducible factor-1alpha, vascular endothelial growth factor expression, and edema in the uterus are mediated by the phosphatidylinositol 3-kinase/Akt pathway. Endocrinology 148: 2363-2374.

Kazi AA, Jones JM and Koos RD (2005). Chromatin immunoprecipitation analysis of gene expression in the rat uterus in vivo: estrogen-induced recruitment of both estrogen receptor alpha and hypoxia-inducible factor 1 to the vascular endothelial growth factor promoter. Mol. Endocrinol. 19: 2006-2019.

Lee A, Christenson LK, Patton PE, Burry KA, et al. (1997). Vascular endothelial growth factor production by human luteinized granulosa cells in vitro. Hum. Reprod. 12: 2756-2761.

Li N, Yi F, Sundy CM, Chen L, et al. (2007). Expression and actions of HIF prolyl-4-hydroxylase in the rat kidneys. Am. J. Physiol. Renal. Physiol. 292: 207-216.

Miyazawa M, Yasuda M, Fujita M, Kajiwara H, et al. (2009). Therapeutic strategy targeting the mTOR-HIF-1alphaVEGF pathway in ovarian clear cell adenocarcinoma. Pathol. Int. 59: 19-27.

Miyazawa M, Yasuda M, Fujita M, Hirabayashi K, et al. (2010). Granulosa cell tumor with activated mTOR-HIF-1alphaVEGF pathway. J. Obstet. Gynaecol. Res. 36: 448-453.

Molitoris KH, Kazi AA and Koos RD (2009). Inhibition of oxygen-induced hypoxia-inducible factor-1alpha degradation unmasks estradiol induction of vascular endothelial growth factor expression in ECC-1 cancer cells in vitro. Endocrinology 150: 5405-5414.

Nastri CO, Ferriani RA, Rocha IA and Martins WP (2010). Ovarian hyperstimulation syndrome: pathophysiology and prevention. J. Assist. Reprod. Genet. 27: 121-128.

Neulen J, Yan Z, Raczek S, Weindel K, et al. (1995). Human chorionic gonadotropin-dependent expression of vascular endothelial growth factor/vascular permeability factor in human granulosa cells: importance in ovarian hyperstimulation syndrome. J. Clin. Endocrinol. Metab. 80: 1967-1971.

Nishimura R and Okuda K (2010). Hypoxia is important for establishing vascularization during corpus luteum formation in cattle. J. Reprod. Dev. 56: 110-116.

Pang X, Wang Z, Yin D and Zhang Z (2011). Overexpression of hypoxia-inducible factor prolyl-hydoxylase attenuated hCG-induced vascular endothelial growth factor expression in luteal cells. Afr. J. Biotechnol. 10: 8227-8235.

Pepperell JR, Porterfield DM, Keefe DL, Behrman HR, et al. (2003). Control of ascorbic acid efflux in rat luteal cells: role of intracellular calcium and oxygen radicals. Am. J. Physiol. Cell. Physiol. 285: 642-651.

Percy MJ, Zhao Q, Flores A, Harrison C, et al. (2006). A family with erythrocytosis establishes a role for prolyl hydroxylase domain protein 2 in oxygen homeostasis. Proc. Natl. Acad. Sci. U. S. A. 103: 654-659.

Ravindranath N, Little-Ihrig L, Phillips HS, Ferrara N, et al. (1992). Vascular endothelial growth factor messenger ribonucleic acid expression in the primate ovary. Endocrinology 131: 254-260.

Richard-Fiardo P, Payen E, Chèvre R, Zuber J, et al. (2008). Therapy of anemia in kidney failure, using plasmid encoding erythropoietin. Hum. Gene. Ther. 19: 331-342.

Shimizu T and Miyamoto A (2007). Progesterone induces the expression of vascular endothelial growth factor (VEGF) 120 and Flk-1, its receptor, in bovine granulosa cells. Anim. Reprod. Sci. 102: 228-237.

Shimizu T, Jayawardana BC, Tetsuka M and Miyamoto A (2007). Differential effect of follicle-stimulating hormone and estradiol on expressions of vascular endothelial growth factor (VEGF) 120, VEGF164 and their receptors in bovine granulosa cells. J. Reprod. Dev. 53: 105-112.

Thomas JP, Dorflinger LJ and Behrman HR (1978). Mechanism of the rapid antigonadotropic action of prostaglandins in cultured luteal cells. Proc. Natl. Acad. Sci. U. S. A. 75: 1344-1348.

Wang Z, Zhu Q, Xia M, Li PL, et al. (2010). Hypoxia-inducible factor prolyl-hydroxylase 2 senses high-salt intake to increase hypoxia inducible factor 1alpha levels in the renal medulla. Hypertension 55: 1129-1136.

Wenger RH, Rolfs A, Marti HH, Guénet JL, et al. (1996). Nucleotide sequence, chromosomal assignment and mRNA expression of mouse hypoxia-inducible factor-1 alpha. Biochem. Biophys. Res. Commun. 223: 54-59.

Wulff C, Dickson SE, Duncan WC and Fraser HM (2001). Angiogenesis in the human corpus luteum: simulated early pregnancy by HCG treatment is associated with both angiogenesis and vessel stabilization. Hum. Reprod. 16: 2515-2524.

van den Driesche S, Myers M, Gay E, Thong KJ, et al. (2008). HCG upregulates hypoxia inducible factor-1 alpha in luteinized granulosa cells: implications for the hormonal regulation of vascular endothelial growth factor $\mathrm{A}$ in the human corpus luteum. Mol. Hum. Reprod. 14: 455-464.

Yaba A, Bianchi V, Borini A and Johnson J (2008). A putative mitotic checkpoint dependent on mTOR function controls cell proliferation and survival in ovarian granulosa cells. Reprod. Sci. 15: 128-138.

Yi F, Xia M, Li N, Zhang C, etal. (2009). Contribution of guanine nucleotide exchange factor Vav2 to hyperhomocysteinemic glomerulosclerosis in rats. Hypertension 53: 90-96.

Young FM, Rodger FE, Illingworth PJ and Fraser HM (2000). Cell proliferation and vascular morphology in the marmoset corpus luteum. Hum. Reprod. 15: 557-566. 
Zhang Z, Yin D and Wang Z (2011a). Contribution of hypoxia-inducible factor-1 $\alpha$ to transcriptional regulation of vascular endothelial growth factor in bovine developing luteal cells. Anim. Sci. J. 82:244-250.

Zhang Z, Yu D, Yin D and Wang Z (2011b). Activation of PI3K/mTOR signaling pathway contributes to induction of vascular endothelial growth factor by hCG in bovine developing luteal cells. Anim. Reprod. Sci. 125: 42-48.

Zhong H, Chiles K, Feldser D, Laughner E, et al. (2000). Modulation of hypoxia-inducible factor 1alpha expression by the epidermal growth factor/phosphatidylinositol 3-kinase/PTEN/AKT/FRAP pathway in human prostate cancer cells: implications for tumor angiogenesis and therapeutics. Cancer Res. 60: 1541-1545. 